\title{
Relación Entre Turismo y Medio Ambiente
}

\section{Celia Weingarten*}

Muy buenas tardes!. En primer lugar, quería manifestar que soy yo la agradecida por haber sido invitada a este importante Congreso, y agradecer fundamentalmente a todos los organizadores y autoridades, la Profesora Cláudia Lima Marques, quien con su gentileza siempre nos atiende en forma tan cálida en este lugar donde gustosamente venimos. Por lo tanto, me honta y me complace enormemente estar hoy en este medio.

Me corresponde a toi, abordar o mostrar las necesarias intetrelaciones que se producen entre el turismo y el medio ambiente. Y cuando hablamos del tutismo, nos estamos refiriendo a una actividad econótnica que hoy día tiene una gran preponderancia en todo el sector económico. Y esto ha justificado o ha ocasionado, un notable aumento tanto a nivel nacional, en cada uno de los países en donde se ejerce y también a nivel internacional.

Constituye actualmente una de las industrias más rentables. Así mismo, constituye un elemento favorable de desarrollo socioeconómico cultural, para los países en donde se ejerce, por el fuerte ingreso de divisas que representa y por otro lado, hay una multiplicidad de servicios que es requerido en la industria turística y por lo tanto es fuente de trabajo, creadores de fuentes de trabajo y por esto los Estados, son los que promueven toda la actividad turística. Así se estima, que en los países desarrollados, aproximadamente un $7 \%$ de la población activa, vive del turismo.

Para Argentina, ha significado en los últimos tiempos, un fuette incremento de divisas y también una posición interesante en toda el área de turismo. Claro que esto se ve favorecido por el hecho de que la actividad turística, la industria turística, requiere de una inversión que no resulta de importancia, ya que lo que se utiliza mayoritariamente son los escenarios naturales y por eso resulta ser de gran rentabilidad. Y esto precisamente ha explicado el númeto de empresas de turismo que han ido aumentando paulatinamente en los últimos tiempos.

\footnotetext{
Profesora de la UBA - Buenos Aires.
} 
Pero, así como por un lado constituye el turismo un factor importante de bienestar y de desarrollo socioeconómico es, al mismo tiempo, un elemento de contaminación y de efectos destructores sobre el medio ambiente.

El turismo es un consumidor de recursos naturales, el término consumidor cuando nació allá en el siglo XVIII, en realidad, o el término consumo mejor dicho, en realidad no tenía las connotaciones que hoy día tiene, sino que tenía connotaciones totalmente contrarias, connotaciones negativas, que significaba saquear, destruir, someter, agotar. Esto es lo que pasa con el turismo, porque se están agotando como se ha dicho ya por los colegas que me han precedido, recursos que son no renovables, recursos que por otra parte son de gran valor y que las empresas utilizan gratuitamente, sin interesarles los impactos negativos que esto produce en el medio ambiente, trasladando entonces el daño a todos los habitantes.

Entonces, si decimos esto, aparece el turismo como agresot de lo que constituye el objeto mismo de su propia existencia. Es decir, que lo que consume son elementos naturales que son imprescindibles para la continuidad de su negocio. El turismo no tiene sentido fuera de un entorno equilibrado y este entorno es precisamente el que esta siendo agredido y cada vez de forma más importante por el ejercicio irracional.

Aquí tengo un ejemplo, y para que tomemos conciencia de la importancia de estos daños, podríamos mencionar algunos de los que causa el turismo, así tenemos que el turismo es un foco importante de contaminación, esto esta provocado, entre otras causas, por el tráfico excesivo de automóviles, es por eso que ahora se están priorizando las áreas peatonales y la restricción de la circulación vial en espacios de alto valor ecológico.

En el medio acuático, se percibe hoy la contaminación de agua provocada por barcos y cruceros turísticos que arrojan petróleo a las superficies de los mares y tíos.

También es frecuente que las poblaciones turísticas arrojen desechos cloacales sin depurar, a los mismos cursos de agua que sirven de atracción turística.

Clato que, los responsables de todo esto se defienden diciendo que en realidad el turismo es tacional, que el obtenido no alcanza para aplicar toda la prevención, los mecanismos de prevención de la contaminación. Y es así que, cada vez que se abre un polo turístico, dado estos escasos recursos que se destinan, ese polo turístico cae, se abre otro, luego decae y así sucesivamente.

Nos encontramos también con una modificación del entomo natural, esto está producido por la construcción de edificios destinados a actividactes vacacionales, hoteles, tiempos compartidos que lo que hacen es modificar la fisonomía de sus paisajes naturales.

Nos encontramos con que muchas zonas tradicionales y residenciales, se han convertido en un centro de servicios y se han emplazado sloppings centers alterando la idiosincrasia urbanística de cada zona. 
Tenemos también la degradación y la contaminación del suelo; esto está provocado por el arrojo de elementos y desperdicios por ejemplo en la playa, que tesultan contaminantes a tal punto que su degradación tequiere décadas.

Destrucción de la fauna y la flora, la cacetía de animales y pájaros, que pueden producit la extinción de especies enteras, además de trastomar el equilibtio biológico y que puede significar perjuicios incalculables para regiones enteras.

Incendios en zonas forestales, causados por el accionar desaprensivo de los turistas y que tiene efectos erosivos en el suelo y alteración de las condiciones de vida animal y vegetal.

Hoy también se están cuestionando determinadas actividades deportivas y que ocupan digamos, un lugar muy importante en todo lo que tiene que ver con la actividad turística, por ejemplo, las canchas de golf son hoy consideradas como un dispendio ecológico de gtan magnitud porque, por ejetraplo el campo de golf lo que hace es consumir territorio con la cantidad de terreno que se requiete para ser realizada. Es un derrochador de agua, ya que necesita gran cantidad de agua por hectárea para su riego, cuando el agua sabemos es un recurso escaso para todos los habitantes y que muchos de ellos no se encuentran actualmente en condiciones de recibitla.

Tienc problemas referidas a la erosión medio ambiental ya que elimina la vegetación original. El consumo de fertilizantes puede contaminar acuíferos, caudales de tíos y torrentes además de afectar o altetar el equilibrio biológico de la flora y la fauna del lugar.

También podriamos mencionar, el impacto cultural e histótico que produce, potque no solamente se contamina el medio ambiente, sino que el medio ambiente incluye también estos aspectos.

Una reciente información periodística de nuestro pais, precisamente difundida antes de nuestra visita a Porto Alegre, daba cuenta de como los turistas iban al sur de nuestro país que es un lugar muy rico y se apropiaban de gran cantidad de restos fósiles de dinosaurios, corales, algunos de ellos formaban grandes organizaciones, otros de ellos se los apropiaban para vender y muchos otros simplemente se los apropiaban como souvenir o regalos, como recuerdo de su estadía.

Entonces, ciertamente podemos hablar hoy de una contaminación turística. Es por eso, que muchos organismos han tomado conciencia entonces de estos peligros, y se hath establecido patámetros específicos de manejo sustentable para esta específica actividad, por ejemplo, establecer la determinada carga en una determinada área de turismo, zonas protegidas, áreas de turismo protegidas y éstos parámetros sustentables para esta actividad han sido, decía antes consensuados por muchísimos organismos.

Claro que, el equilibrio del que hablan las Constituciones, esto es la harmonización del medio ambiente con la actividad económica, requiere de políticas interdisciplinarias. Pero nos encontramos con las empresas, que están apostando permanentemente a una rentabilidad económica, sin tener en cuenta que existen límites reales al uso de esos recursos naturales. 
Así las empresas turísticas utilizan el medio ambiente de forma discrecional, no asumen los costos de prevención y exteriorizan los riesgos de la actividad a toda la sociedad. Imponen el daño ambiental, a toda la sociedad y, mayoritariamente eligen siempre a los países más débiles en su protección y más económicos.

Hoy el lema no es, el que contamina paga sino, invertir, para no contaminar.

Ahora bien, este modelo de empresa, está siendo hoy afortunadamente desplazada por otros modelos donde este foco que supuestamente existe entre lo que es la rentabilidad económica y los costos para la prevención del medio ambiente, no es tal. Es decir, estos dos términos no son absolutamente inconciliables.

Esto entonces nos conduce a otro tópico que es la ética y el cuidado del medio ambiente como factor de posicionamiento y de rentabilidad económica.

Porque digo esto, porque la calidad del medio ambiente es hoy, una de las preocupaciones del turista. Tanto en la elección del destino, como en la satisfacción que pretende logtar. $O$ vale decir, lo que es lo mismo, los aspectos que más causan insatisfacción en los turistas, se relacionan en este momento con la calidad del medio ambiente.

¿Cuáles son las satistacciones del turista? Las expectativas del turista son contat con la infraestructura adecuada, playas limpias, aguas limpias, un paisaje agradable.

Si un turista se encuentra con un paisaje deteriorado, obviamente esto conduce a lo contrario, la insatisfacción del turista.

Por lo tanto, todos estos factores hacen, que la concentración de los temas ambientales deban ser vistos no ya como una carga sino cono una indudable ventaja competitiva para el sector empresario y para los países.

Ofrecer hoy día, un producto con sensibilidad hacia los conceptos medioambientales, permite desarrollat importantes ventajas competitivas, o sea posicionan a una empresa de manera más ventajosa tespecto de la otra y posibilita entonces una attacción de clientela mayor y además de esto crea una fidelidad a la empresa y a la marca.

Esto es beneficioso, tanto para los paises como para las empresas que ejercen el turismo. Para los países obviamente, cuando tienen problemas ambientales, esto resulta ser muy poco atractivo para las inversiones en el campo del turisno y también en el mismo sentido para las empresas de turismo que en general son los grandes propietarios de líneas aéteas, cadenas de hoteles.

La aplicación de estos principios del ecomarketing es decir, el diseño de un producto turístico apoyada en claves ecológicas, se convierte entonces en una estrategia comercial al crear, una imagen positiva ante los clientes potenciales. $Y$ esto, está agregando un valor a esa empresa y a ese país. 
Para que la empresa le conforma lo que se denomina el capital intangible, hoy los bienes tangibles están siendo sustituidos rápidamente por los bienes intangibles. Y por lo tanto esto les constituye a las empresas como un recurso a más del que pueden valerse así como si uno estuviera hablando del capital, del trabajo, etc. Por lo tanto, lo que decía antes, estos dos término no son inconciliables como se pretende hacer ver, sino que hoy se marcha hacia un nuevo modelo de empresa, basada en la ética y la responsabilidad social.

En cuanto a las responsabilidades involucradas, nos encontramos con que los agentes que están ligados a esta actividad son fundamentalmente el turista, las empresas de viaje y también obviamente el Estado en sus distintos roles y funciones.

Y para las empresas interesa marcar un aspecto en particular dado lo avanzado del tiempo y lo pautado por los coordinadores para dentro del panel.

Muchas empresas turisticas, llevan a cabo actividades, organizan servicios turísticos que en sí mismos tesultan ser contaminantes, por ejemplo, una actividad que tiene por objeto la caza de determinados animales en rías de extinción.

En realidad nos estamos refitiendo a una sociedad con objeto ilícito, aunque en apariencia tenga un objeto lícito.

Entonces esto, por lo menos en nuestro país, recibe distintas soluciones en el derecho societario, que nos habla de la responsabilidad solidatia de los administradores y socios y la liquidación de oficio y pérdida de las utilidades para las empresas y también, extensión de la responsabilidad a los controlantes.

Claro que, sin perjuicio de estas notmas, deberiamos adoptar otras porque lo que debe tenerse en cuenta es que cuando una empresa está contaminando está obteniendo una sobreganancia ilegitima, ilícita, a costa de los demás, es decir, se entiquece econónicamente a costa del empobrecimiento de la sociedad.

Por lo tanto sería importante, privar de esta ganancia, a las empresas que han opetado de esta manera. Sería una forma de aplicar la teoría del entiquecimiento sin causa.

Y, hay una modalidad que tiene que ver con el desplazamiento masivo de los turistas, que son los denominados paquetes turísticos esto es, un conjunto de servicios, hotelería, aeronavegación, servicio aéteo, que se ofrecen por un precio único. Entonces acá nos encontramos con varios partícipes, varios sujetos que están manufacturando un servicio, un servicio turístico, entonces cuando uno se indaga acerca de quien es el responsable por ejemplo de los actos de un turista que agrede el patrimonio natural, el patrimonio cultural, hablamos de la responsabilidad de los organizadores peto, frente a estos sistemas actuales que se están conformando, porque hoy estamos alejados de ese paradigma contractual de relaciones individuales y personalizadas, para dar paso a esta construcción de sistemas, redes contractuales que unen las distintas cmpresas y estas distintas empresas están obteniendo en forma directa o indirecta una importante ganancia. 
Entonces, desde un concepto objetivo de empresas que están conformadas por distintas sociedades porque el rasgo actual en esta pos-modernidad es la actividad económica grupal, es decir, las relaciones de organización es lo que tipifica a esta nueva economía. Por lo tanto, todos estos aspectos funcionales y econónicos deben prevalecer por sobre las manifestaciones externas de esos supuestos vínculos contractuales que se muestran como singulares, para así fragmentar la responsabilidad.

Esto quiere decir que hay una responsabilidad solidaria de todos los que participan de la manufactura de este paquete turístico.

Y por último, el Estado, el Estado que tiene una gran preponderancia. El Estado que es el garante de la preservación del medio ambiente y que es el obligado a planificar legislativamente todas estas cuestiones y no solamente lo ligado a planificarlo sino también a ejercer la policía ambiental necesaria sobre este terreno.

Pero hay aqui un punto importante sobre el cual creo que deberíamos reflexionar. algún instante, y es que, la actividad turística hoy trasciende los intereses nacionales y tiene efectos transfronterizos, es decir que los efectos de la contaminación se producen también en otros países.

Y un fenómeno que se da en la actualidad, es que los países desartollados, son los ptincipales emisores de turismo, se está generando una gran cantidad de flujo turístico desde los países desarrollados a los subdesarrollados, que reciben esos turistas que están en una mejor posición econónica y que quizá no tenga una actuación respetuosa del medio ambiente.

Entonces decía, esto nos abre un interrogante y nos obliga a pensar en soluciones, porque la pregunta es: ¿Quién asume entonces los costes del mantenimiento y la reparación, la composición del medio ambiente? Los países emisores del turismo o los países receptores y en definitiva serán toda la sociedad, usuarios y no usuarios.

De lo que se trata en definitiva, es de tratar de encontrar soluciones más equitativas que morigeren la desigualdad entre páses ricos y países pobres, que pueda conducir a un turismo sustentable y además que pueda evitar estos efectos destructores de uno de los peligtos que hoy amenazan a la humanidad.

Muchísimas gracias por su atención. 